and Pneumocystis carinii. Barium swallow showed extensive deep ulceration with formation of plaques, consistent with oesophageal candidiasis, and a Mantoux test ( 1 in $10000 \mathrm{U}$ ) was positive, but there was no reaction to intradermal candida.

Two weeks after presentation the total circulating $T$ cell count was $1 \cdot 2 \times 10^{9} / 1$, T $40.56 \times 10^{9} / 1$, and T8 $0.44 \times 10^{9} / 1$; and antibodies to the human T cell lymphotropic virus type III (HTLV-III) were detected by membrane immunofluorescence. These results confirmed the diagnosis of AIDS based on the finding of pulmonary $M$ tuberculosis with oral and oesophageal candidiasis accompanied by characteristic immunological changes and evidence of infection with HTLV-III.

Five weeks' treatment with ethambutol, pyrazinamide, rifampicin, isoniazid, nystatin, and ketoconazole resulted in no clinical improvement and a persistent fever. Two hours after administration plasma rifampicin concentrations, measured by high pressure liquid chromatography after extraction of plasma with methylene chloride, were $<0.5 \mathrm{mg} / \mathrm{l}$ when rifampicin and ketoconazole were given concurrently, $2 \mathrm{mg} / \mathrm{l}$ when given 12 hours apart, and $3 \mathrm{mg} / \mathrm{l}$ after intravenous rifampicin only. Serum ketoconazole concentrations measured by a broth dilution bioassay were $0 \mu \mathrm{g} / \mathrm{l}$ when the oral doses were separated by 12 hours and $0.3 \mathrm{mg} / \mathrm{l}$ when oral ketoconazole was given 12 hours after intravenous rifampicin. After the introduction of intravenous rifampicin the patient's condition improved and his fever resolved. After two weeks oral amphotericin was substituted for ketoconazole, and he remained without fever when oral rifampicin was restarted.

\section{Discussion}

$M$ tuberculosis causing pulmonary disease in association with AIDS has been reported mainly in the Haitian population in America suffering from AIDS. ${ }^{1-3}$ As a result of the prevalence of $M$ tuberculosis in the British population we may expect to see further cases of pulmonary $M$ tuberculosis in people suffering from AIDS in Britain. There may be variation in radiographic features, and in our case the radiograph of the chest showed more severe interstitial w changes than those found in other series. ${ }^{4}$

A drug interaction was also observed in our patient between rifampicin and ketoconazole, leading to subtherapeutic serum $C$ concentrations and poor clinical response to treatment. In a $\widehat{\supset}$ previous report of this interaction a reduction in absorption of $\overline{\bar{J}}$ rifampicin was postulated. ${ }^{5}$ Our limited number of measurements suggest that the relation may be more complex but that intravenous treatment is effective when judged on clinical criteria. Ketoconazole is the mainstay of treatment for candidiasis in patients with AIDS, : which responds poorly to topical agents. Ketoconazole and rif- $\overline{\bar{v}}$ ampicin are likely to be used together in this context, and it is important that this drug interaction is studied in greater detail.

We thank Dr P A Toseland and Professor D W R Mackenzie for measurement of drug concentrations; Dr A J Pinching for reviewing the article; and Miss R A Mace for preparing the manuscript.

\section{References}

1 Viera J, Frank E, Spira TJ, Landesman SH. Acquired immune deficiency in Haitians. $N$ Engl $\mathcal{f}$ Med 1983;308:125-9.

2 Pitchenik AE, Fischl M, Dickinson GM, et al. Opportunistic infections and Kaposi's sarcoma among Haitians: evidence of a new acquired immunodeficiency state. Ann Intern Med 1983;98: 277-84

Pape $\mathrm{W}$, Liataud $\mathrm{B}$, Thomas $\mathrm{F}$, et al. Characteristics of the acquired immunodeficiency syndrome Haiti. N Engl F Med 1983;309:945-50.

4 Pitchenik AE, Rubinson HA. The radiographic appearance of tuberculosis in patients with the acquired immune deficiency syndrome (AIDS) and pre-AIDS. Am Rev Respir Dis 1985:131: 393

5 Englehard D, Stutman HR, Marks MI. Interaction of ketoconazole with rifampicin and isoniazid. N Engl f Med 1984;311:1681-3.

Accepted 17 fuly 1985)

\title{
Persistence of antibrain antibodies in cerebrospinal fluid during plasmapheresis for multiple sclerosis
}

\author{
B RYBERG, R PIRSKANEN
}

\begin{abstract}
A man with chronic progressive multiple sclerosis received a 10 day course of treatment with adrenocorticotrophic hormone without beneficial effect. He then received six sessions of plasmapheresis, again without improvement. Treatment with adrenocorticotrophic hormone had no effect on serum antibrain antibody titres, but plasmapheresis virtually eliminated the antibodies from serum and caused a fall in serum IgG concentrations; neither treatment had any effect on the IgG concentration and antibody titre in the cerebrospinal fluid.

Treatment with plasmapheresis may fail in patients with multiple sclerosis because it does not remove antibrain antibodies from the intrathecal space.
\end{abstract}

Department of Neurology, University of Lund, Sweden

BJÖRN RYBERG, MD, senior research fellow

Department of Neurology, South Hospital, Karolinska Institutet, S-100 64 Stockholm, Sweden

RITVA PIRSKANEN, MD, senior lecturer

Correspondence to: Dr Ryberg.

\section{Introduction}

Plasma exchange might well be expected to work in multiple sclerosis by removing humoral factors with gliotoxic, myelinotoxic, $\frac{\dot{5}}{3}$ and neuroelectric blocking properties; circulating immune complexes; and complement fixing antibrain antibodies of various specificities. ' Such treatment can reduce serum neuroelectric blocking activity ${ }^{2}$ and cerebrospinal fluid IgG concentrations in patients 옥 with multiple sclerosis, ${ }^{3}$ but so far therapeutic success has been $\stackrel{N}{\circ}$ limited. ${ }^{4}$

\section{Case report}

A 38 year old man was in the chronically progressive phase of multiple sclerosis, which had first developed in 1975 as a relapsing-remitting $\stackrel{C}{\bullet}$ disorder. Diagnosis was substantiated by clinical, neurophysiological, and $\overparen{D}$ cerebrospinal fluid findings. A 10 day course of treatment with adreno- ?+ corticotrophic hormone in March 1982 had no effect on his signs and 7 symptoms, which included reduced visual acuity, moderate spastic para- $O$ paresis, sensory disturbances of hands and legs, urgency of micturition, exaggerated tendon reflexes, and extensor plantar responses.

Because of increasing disability he was treated with six sessions of plasmapheresis in May and June 1982. On each occasion four litres of plasma were removed and replaced with electrolytes and albumin solution. There $\delta$ was no improvement in clinical state or brain stem auditory evoked response, and his condition continued to worsen. 
Samples of serum and cerebrospinal fluid obtained before, during, and after the period of treatment with adrenocorticotrophic hormone and plasmapheresis were assayed for complement fixing antibrain antibodies ${ }^{1}$ and found to react with homogenate of human white matter $(1: 30 \mathrm{wt} / \mathrm{vol}$ in veronal buffer). The IgG class of the antibodies was shown by absorption and elution on Protein A-Sepharose CL-4B (Pharmacia, Sweden). Before plasmapheresis the IgG index was 0.74 and the cerebrospinal fluid antibody index ${ }^{5}$ for antibrain antibodies was $27 \cdot 4$ (upper normal limit $=2$ ). Whereas treatment with adrenocorticotrophic hormone did not seem to affect the serum level of antibrain antibodies, plasmapheresis caused them to be virtually eliminated from serum concomitant with a pronounced drop in
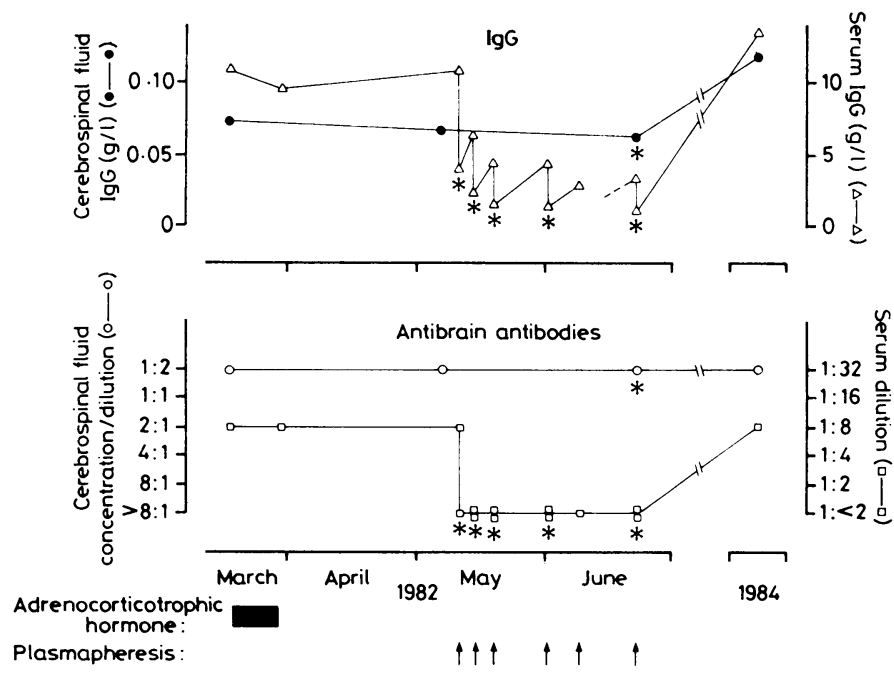

IgG concentrations and antibrain antibodies before, during, and after plasmapheresis. Before titration of antibodies cerebrospinal fluid was concentrated and rediluted to give multiples of original IgG concentration.

^Samples obtained within 12 hours after plasmapheresis. serum IgG concentrations. The antibody titre and IgG concentration in cerebrospinal fluid, however, remained unchanged (figure). Cerebrospinal fluid obtained just after the last session of plasmapheresis showed the same oligoclonal IgG pattern as cerebrospinal fluid obtained shortly before treatment.

\section{Comment}

The important finding in this study was the persistence during plasmapheresis of antibrain antibodies in cerebrospinal fluid along with an essentially unchanged IgG concentration and oligoclonal IgG pattern in this fluid. These observations are consistent with intrathecal production of both IgG and antibrain antibodies. This conclusion is supported by the high IgG and antibody indexes.

Thus the therapeutic failure of plasmapheresis in this and other patients with multiple sclerosis may be related to the inability of this method to remove antibrain antibodies, and perhaps other humoral factors, from the compartment where they probably react with the central nervous system-that is, the intrathecal space. The patients with multiple sclerosis most likely to profit from plasmapheresis may be those with a predominantly extrathecal distribution of such factors.

\section{References}

1 Ryberg B. Antibrain antibodies in multiple sclerosis. Relation to clinical variables. $\mathcal{F} \mathrm{Neurol} \mathrm{Sci}$ 1982;54:239-61.

2 Stefoski D, Schauf CL, McLeod BC, Haywood CP, Davis FA. Plasmapheresis decreases neuroelectric blocking activity in multiple sclerosis. Neurology 1982;32:904-7.

3 Caparelli R, Inzitari D, Sita D, et al. Plasmapheresis in multiple sclerosis: cerebrospinal fluid changes after treatment. In: Gonsette RE, Delmotte P, eds. Immunological and clinical aspects of multiple sclerosis. Lancaster: MTP Press, 1984:57-60.

multiple sclerosis. Lancaster: MTP Press, 1984:57-60.
4 Schumak KH, Rock GA. Therapeutic plasma exchange. N Engl f Med 1984;310:762-71

4 Schumak KH, Rock GA. Therapeutic plasma exchange. N Engl f Med 1984;310:762-71.
5 Ryberg B. Extra- and intrathecal production of antinerve and antibrain antibodies in Guillain-Barre Ryberg B. Extra-and intrathecal production of antinerve and antibrain antibod
syndrome: evaluation by an antibody index. Neurology 1984;34:1378-81.

(Accepted 17 fuly 1985

\title{
Are coronary artery spasm and progressive damage to the heart associated with the hyperventilation syndrome?
}

\author{
LEISA J FREEMAN, P G F NIXON
}

\begin{abstract}
A case of coronary artery vasospasm was studied in a man with a four year history of angina. He had evidence of symptomatic hyperventilation during a spontaneous episode of chest pain. When asked to hyperventilate the pain in his chest and ST elevation were reproduced in the same leads as occurred during the spontaneous attack. This may be the first reported case of spontaneous hyperventilation producing vasoconstriction, and the patient's previous admissions to the coronary care unit may have been associated with coronary vasospasm induced by hyperventilation.

When patients with variant angina report pains in the chest in association with dizziness and breathlessness hyperventilation
\end{abstract}

Cardiac Department, Charing Cross Hospital, London W6 8RF

LEISA J FREEMAN, MRCP, registrar

PG F NIXON, FRCP, consultant cardiologist

Correspondence to: Dr Freeman should be considered to be a possible cause of the symptoms. As coronary vasospasm is increasingly implicated in angina after myocardial infarction the role of hyperventilation should be considered more often.

\section{Introduction}

Coronary vasospasm, either spontaneous or provoked at catheterisation, has been confirmed as the pathogenic mechanism in variant angina.' We describe a patient with coronary artery vasospasm and suggest an aetiological role for the associated hyperventilation.

\section{Case report}

A 62 year old foreman was admitted for assessment of chest pain. He had a four year history of exertional, nocturnal, and rest angina. Breathlessness and giddiness were associated with the pain. He had had 14 admissions to a local coronary care unit with suspected myocardial infarctions without changes in enzyme concentrations to confirm the diagnosis. ST elevation was noted on at least six occasions. On the first eight admissions the electro- 